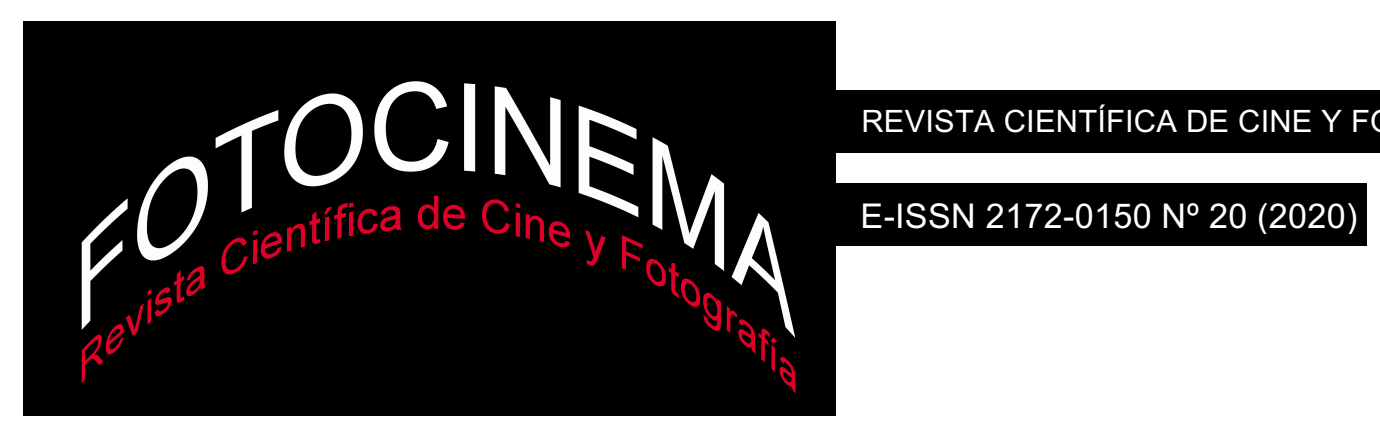

\title{
Laberintos del recuerdo: La representación de la memoria en ¡Olvídate de mí!
}

\section{Labyrinths of remembrance. The representation of memory in Eternal Sunshine of the Spotless Mind}

\section{Resumen}

María del Rincón

Universidad de Navarra, España mariadelrincon@gmail.com

Efrén Cuevas

Universidad de Navarra, España ecuevas@unav.es

María Noguera

Universidad de Navarra, España mnoguera@unav.es

El artículo propone un estudio del filme iOlvídate de mí! como caso paradigmático de "película de memoria". La cinta, dirigida por Michel Gondry y con guion de Charlie Kaufman, aborda la representación fílmica de la memoria personal de una manera lograda, en su doble condición de objeto y proceso. El análisis aborda en primer lugar cómo la memoria emerge en la película como eje temático de la representación fílmica. Después se analiza la estructura del relato, construida a partir distintas líneas narrativas que se entrecruzan constantemente y que provocan una evidente complejidad narratológica. Y, por último, se atiende a los tres rasgos más característicos de las películas de memoria: la subjetividad, la indiscernibilidad temporal y la performatividad. La forma en la que estos tres conceptos convergen en iOlvídate de mí! convierte este filme en un excelente ejemplo de las posibilidades a las que se abre la representación fílmica de la memoria personal.

\begin{abstract}
The article proposes a study of the film Eternal Sunshine of the Spotless Mind as a paradigmatic case of "memory film". The film, directed by Michel Gondry and written by Charlie Kaufman, addresses the filmic representation of personal memory in an accomplished way, in its double condition of object and process. The analysis first deals with how memory emerges in the film as its thematic axis. Then the structure of the story is analyzed, built with different narrative lines that constantly intersect and that cause an obvious narratological complexity. Finally, the three most characteristic features of memory films are addressed: subjectivity, temporal indiscernibility and performativity. The way in which these three features converge on Eternal Sunshine of the Spotless Mind makes this film an excellent example of the possibilities available in cinema for the representation of personal memory.
\end{abstract}

Palabras clave: Memoria; película de memoria; narratología; subjetividad; indiscernibilidad temporal; performatividad.

Keywords: Memory; memory film; narratology; subjectivity; temporary indiscernibility; performativity. 


\section{1. ¡Olvídate de mú! como película de memoria}

La memoria es una categoría significativa dentro de cualquier narración, en cuanto que la construcción de personajes suele apoyarse en su pasado y en el modo en que estos lo recuerdan. En el relato cinematográfico, el pasado se recupera normalmente a través de los diálogos y de las vueltas al pasado (los flashbacks) sustentando así la narración del presente del personaje. Sin embargo, el cine puede también subrayar la propia facultad humana de la memoria, tomándola como objeto y proceso, y no como mero apoyo narrativo. Las herramientas fílmicas son especialmente aptas para captar el carácter performativo inherente a la memoria, en el que se entrelazan distintas capas de tiempo -el pasado es siempre recuperado desde un presente-, lo que en última instancia origina una cierta indiscernibilidad temporal. El presente artículo pretende analizar un caso paradigmático de una película en la que se despliegan este tipo de estrategias: iOlvídate de mú! (Eternal Sunshine of the Spotless Mind, 2004), dirigido por Michel Gondry y con guion de Charlie Kaufman.

Siguiendo la propuesta de autores como Erll (2011), MacDougall (1992, 1998), Ciancio (2013) o Grass (2009), enmarcaremos esta cinta dentro de las llamadas películas de memoria, cuestión que ya abordamos en un estudio anterior (2017). Definimos entonces las películas de memoria como aquellos filmes -de ficción o documental- cuyo tema principal es la acción de recordar; filmes que recrean el tiempo subjetivo del protagonista que recuerda, desplegando una tensión entre presente y pasado, a través de una peculiar expresión estética destinada a poner en imágenes el modo en el que los recuerdos se articulan en la mente (2017, pp. 177-182). Es posible, por tanto, hablar de dos señas de identidad en este tipo de películas: su exploración de la naturaleza de la memoria como objeto de representación y su indagación en las formas de enunciación de la memoria.

Para analizar iOlvídate de mí! en cuanto película de memoria, estructuraremos nuestro estudio en tres etapas: primero abordaremos cómo la memoria personal constituye el principal tema de representación de la película; después estudiaremos el modo en que los aspectos formales 
secundan esta temática, partiendo de su configuración narrativa; y finalmente examinaremos cómo se despliegan en esta obra los tres rasgos característicos que hemos señalado para las películas de memoria: la subjetividad, la indiscernibilidad temporal y la performatividad (2017, pp. 182-186).

\section{La memoria personal como tema de la representación}

iOlvídate de mí! cuenta la historia de Joel Barrish, quien decide borrar de su memoria los recuerdos concernientes a su ex-novia, Clementine Kruczynski, recurriendo a una tecnología ofrecida por la empresa Lacuna. La película muestra principalmente lo que García-Sahagún ha descrito como un proceso de borrado de la memoria "a la carta" (2016, p. 189), que se lleva a cabo durante una noche en casa de Joel por dos técnicos de Lacuna (Stan y Patrick). A la vez, recrea el modo en que los recuerdos van desapareciendo dentro de la mente del protagonista y su lucha, mientras permanece dormido, por intentar frenar el borrado, al recordar los buenos momentos compartidos con Clementine. Esta breve sinopsis ya evidencia que la película trata sobre la memoria como objeto -al representar los recuerdos de Joel- y sobre la memoria como proceso - a través tanto del proceso de borrado como de los intentos de Joel por detenerlo-. Así lo entiende también en cierto modo Sperb, quien encuadra esta obra dentro de una tendencia reciente que ha generado varios filmes sobre la memoria, pero la distingue de otras cintas temáticamente similares por captar la esencia de la memoria psicológica, cimentada en sus aspectos subjetivos y afectivos, que devuelven la representación cinematográfica de la memoria al marco de la capacidad personal de rememorar (2005).

Como punto de partida, podemos afirmar que iOlvídate de mí! propone dos formas de entender la memoria. Por un lado, si se atiende exclusivamente a la sinopsis de la obra, podríamos concluir que la tecnología facilitada por Lacuna está orientada a eliminar un tipo de recuerdos que son concebidos como archivos físicos o como una realidad meramente cerebral, tal como afirma Vidal (2007, pp. 96-109). Cuando el Dr. Howard Mierzwiak explica a 
Joel el funcionamiento del borrado, indica que, en primer lugar, habrán de trazar un mapa cerebral para situar el lugar de los recuerdos en el cerebro. Tras enfrentar a Joel con distintos objetos vinculados al pasado -que son presentados como signos de supervivencia de la memoria o memorabilia-, estos generarán en él respuestas afectivas, que se traducen en puntos cerebrales iluminados, registrados mediante un escáner, que posteriormente serán eliminados por la noche. Si bien el acto de recordar es considerado como un fenómeno íntimamente ligado a los afectos, pues se pide a los pacientes que narren sus recuerdos y se enfrenten a esos signos de supervivencia cargados de significado, el resultado de ese acto de recordar se reduciría a la generación de imágenes mentales estáticas y fijadas.

Sin embargo, durante la técnica de borrado de los recuerdos, los espectadores somos testigos de cómo Joel percibe este proceso que conduce al olvido. La película muestra, por tanto, cómo la memoria no se reduce a una mera localización de los recuerdos almacenados, sino que establece un vínculo con el presente, genera una actualización de los eventos pasados, como afirman las teorías de Bergson (1946) y Deleuze (1987, 1991). Joel se enfrenta a los recuerdos que el equipo de Lacuna va borrando desde una perspectiva presente y autoconsciente, como quedará de manifiesto al considerar el modo en que la película representa esas imágenes del pasado.

Además, iOlvídate de mí! contrasta la experiencia de quienes se han sometido al sistema de borrado con la teoría sustentada por el Dr. Howard Mierzwiak respecto a este proceso. La práctica de Lacuna se sustenta en el presupuesto de que al suprimir los recuerdos se elimina del cerebro toda referencia a los eventos o personas "borrados”. Sin embargo, se advierte cómo en los personajes perviven ciertos resquicios de carácter afectivo, pues pese a no recordar lo vivido, siguen igualmente marcados por el pasado, que configura su identidad y les conduce a reiterarse en sus decisiones previas. Clementine y Joel vuelven a enamorarse, igual que Mary vuelve a hacerlo del Dr. Mierzwiak, guiados por esos "restos afectivos" que el procedimiento no tiene en cuenta. Este contraste entre la visión estática y archivística sostenida por el personal de Lacuna y la memoria performativa y subjetiva que 
observamos en Joel, da lugar a esa especie de hechizo que provoca, tras el borrado, que los personajes se enfrenten de nuevo a situaciones que el proceso de eliminación debería evitar, como el reencuentro en Montauk, causado aparentemente por la última frase de Clementine a Joel en la casa de la playa.

iOlvídate de mí! supone, por tanto, una reflexión acerca de la memoria que contrapone diferentes teorías sobre el acto de recordar y que concluye sustentando un tipo de memoria subjetiva y en construcción. La película plantea una representación de la memoria personal que se entiende como un acto subjetivo mediante el cual el personaje principal actualiza, desde su contexto y conocimiento presentes, los eventos del pasado. Puesto que esta concepción es presentada mediante recursos formales no convencionales, la película también involucra al espectador en la generación de los recuerdos, proponiendo un estudio certero sobre el acto mnemónico, tal como veremos al analizar el modo en el que la memoria queda representada.

\section{Representación formal de la memoria}

Una vez identificados los ejes temáticos de iOlvídate de mí!, pasamos a realizar un análisis de las decisiones formales que sustentan, mediante la narración y los recursos visuales, la representación de las características principales de la memoria personal. Analizaremos en primer lugar la estructura narrativa de la película para identificar después el modo en que la obra traduce los rasgos esenciales del acto mnemónico mediante distintas herramientas fílmicas.

\subsection{Estructura narrativa}

Para poder analizar la forma en que esta película representa la memoria y sus cualidades principales, comenzaremos explicando el modo en que la obra se estructura narrativamente, tarea que abordaremos siguiendo la propuesta metodológica de Gerard Genette (1971) adaptada al cine por autores como Gaudreault y Jost (1995) o Cuevas (2001, 2009). 
La estructura narrativa de iOlvídate de mí! presenta una indudable complejidad, pues el relato se construye según varias líneas narrativas que se entrecruzan constantemente. Presentamos a continuación un esbozo del modo en que se articulan las dos categorías genettianas básicas sobre las que se sustenta el análisis narratológico: la historia, que sigue una ordenación cronológica ideal, y el relato, tal y como se presenta al espectador. La historia aborda la relación de Joel y Clementine, que se desarrolla entre el verano de 2002, cuando se conocen en una fiesta en la playa, hasta la mañana del 16 de febrero de 2004, en la que, tras descubrir que ambos se han sometido a un proceso de borrado de memoria, deciden dar otra oportunidad a su relación. La forma en que esta historia está relatada se estructura de modo fragmentario y enredado. Para facilitar su comprensión, la siguiente tabla (F1) sitúa en orden cronológico los distintos eventos del relato marco, que hemos situado en el "presente" del 11 al 16 de febrero de 2004. Los momentos de la relación de Joel y Clementine sucedidos antes del proceso de borrado serán considerados, por lo tanto, como vueltas al pasado.

\begin{tabular}{|l|l|}
\hline $\mathbf{1 1}$ feb 2004 & $\begin{array}{l}\text { Joel visita a Clementine en la librería y ella no le reconoce. Sus } \\
\text { amigos le cuentan que Clementine ha borrado su memoria. }\end{array}$ \\
\hline $\mathbf{1 2}$ feb 2004 & Joel decide borrar también sus recuerdos. \\
\hline \multirow{213}{*}{ feb 2004 } & $\begin{array}{l}\text { Joel lleva a Lacuna objetos que le recuerdan a Clementine, } \\
\text { donde trazan el mapa mental de sus recuerdos. }\end{array}$ \\
\cline { 2 - 3 } & $\begin{array}{l}\text { Durante la noche y en su casa, Joel es sometido al proceso de } \\
\text { borrado, que termina poco antes del amanecer. } \\
\text { Mary descubre que se sometió al mismo procedimiento para } \\
\text { eliminar de su memoria una relación pasada con el doctor } \\
\text { Mierzwiak. }\end{array}$ \\
\hline $\mathbf{1 5}$ feb 2004 & $\begin{array}{l}\text { Joel despierta y decide ir a Montauk, donde coincide con } \\
\text { Clementine en el tren. } \\
\text { Mary abandona Lacuna, roba los dosieres de los pacientes y les } \\
\text { envía por correo las cintas de sus respectivas grabaciones. }\end{array}$ \\
\hline \multirow{2}{*}{ Joel y Clementine van al río Charles por la noche. } \\
\hline & $\begin{array}{l}\text { Joel lleva a Clementine a su casa. Allí ella encuentra la cinta } \\
\text { que le ha enviado Mary. Después la escuchan juntos en el } \\
\text { coche y discuten. Joel termina echando a Clementine del } \\
\text { vehículo. } \\
\text { Joel encuentra su cinta en su casa. Clementine va a casa de } \\
\text { Joel y deciden darse una segunda oportunidad. }\end{array}$ \\
\hline
\end{tabular}

F1. Eventos del relato marco del 11 al 16 de febrero de 2004. Elaboración propia 
Tras esta descripción del relato marco, podemos analizar ahora el modo en que los hechos son narrados en la película. El relato arranca con una secuencia que tiene lugar el 14 de febrero de 2004. Joel despierta en su cama luciendo un pijama azul. Al salir de casa observa una abolladura en su coche, que achaca al vehículo aparcado a su lado. Toma el coche y va a la estación de tren, donde siente unas ganas incontrolables de visitar Montauk. Allí coincide con Clementine, con la que entabla una conversación en el tren de vuelta y a quien ofrece llevar en coche a su casa. Tras despedirse y llamarse por teléfono conciertan una cita para la noche siguiente, en la que van al río Charles, que está congelado. En la mañana del día 16 de febrero Joel lleva a casa a Clementine, y esta le pide pararse antes en la suya para recoger su cepillo de dientes.

A esta secuencia le sigue una escena nocturna en la que se observa a un Joel desconsolado, conduciendo entre lágrimas hacia su casa mientras se despliegan los títulos de crédito. Se intuye un salto temporal que produce cierto extrañamiento en el espectador. Joel llega a casa y se encuentra con un vecino que le pregunta si tiene planes con Clementine para San Valentín. Si bien podría pensarse que la secuencia anterior tenía lugar en un pasado previo, en realidad es esta escena nocturna la que sucede con antelación, en la noche anterior del 13 de febrero de 2004. Esta parte del filme, que se extiende desde el minuto 17 hasta casi el final, concluye en el punto en que comienza la película: Joel se despierta en su cama la mañana del 14 de febrero con un pijama azul, tras haber sido sometido a un proceso de borrado de su memoria. Cuando en el minuto 93 volvemos a ver cómo Joel se encuentra con su coche abollado, comprendemos entonces que la cinta había comenzado con una ida al futuro o prolepsis, pues no había mostrado el primer encuentro de Joel y Clementine, sino su reencuentro el 14 de febrero de 2004 tras el procedimiento de borrado.

Después de esa escena, la parte final, como se ha explicado sumariamente en el esquema, muestra cómo Mary abandona su trabajo en Lacuna al haber descubierto que también fue sometida a un proceso de borrado y se lleva consigo las fichas y las cintas de los pacientes. A continuación, el relato 
presenta una elipsis que omite el contenido de la escena inicial del filme hasta el momento en que Clementine entra en su casa para recoger el cepillo de dientes el 16 de febrero. Al salir, Clementine recoge el correo y encuentra la cinta enviada por Mary con su propio relato sobre su relación con Joel que además escucha con este dentro de su coche. Joel despide a Clementine enfadado, pensando que se trata de una broma de mal gusto. Cuando Joel regresa a su casa descubre la cinta con su versión de la relación y después de una pelea, la pareja finalmente decide darse una segunda oportunidad.

Como se ha podido comprobar, el relato queda conformado por una escena de arranque en forma de prolepsis interna que muestra los eventos de los días 14, 15 y la mañana del 16 de febrero, a la que le sigue el proceso de borrado mental y sus consecuencias, situado entre la noche del 13 al 14, para continuar en la mañana del 16 de febrero, en la que se cierra la trama principal. Pero la película presenta otra dificultad narrativa añadida, puesto que durante el proceso de borrado se ven las escenas rememoradas y después eliminadas de la mente de Joel en un orden cronológicamente inverso y con ciertos saltos y quiebros temporales. Estas escenas de los recuerdos que están siendo suprimidos comienzan con los sucesos del 11 de febrero de 2004, cuando Joel descubre que Clementine ha borrado su memoria, y se trasladan a varios puntos de su relación, iniciada en el verano de 2002, y a varios momentos de la infancia de Joel. El relato presenta, en definitiva, una organización narrativa que podría resumirse gráficamente en el siguiente esquema (F2):

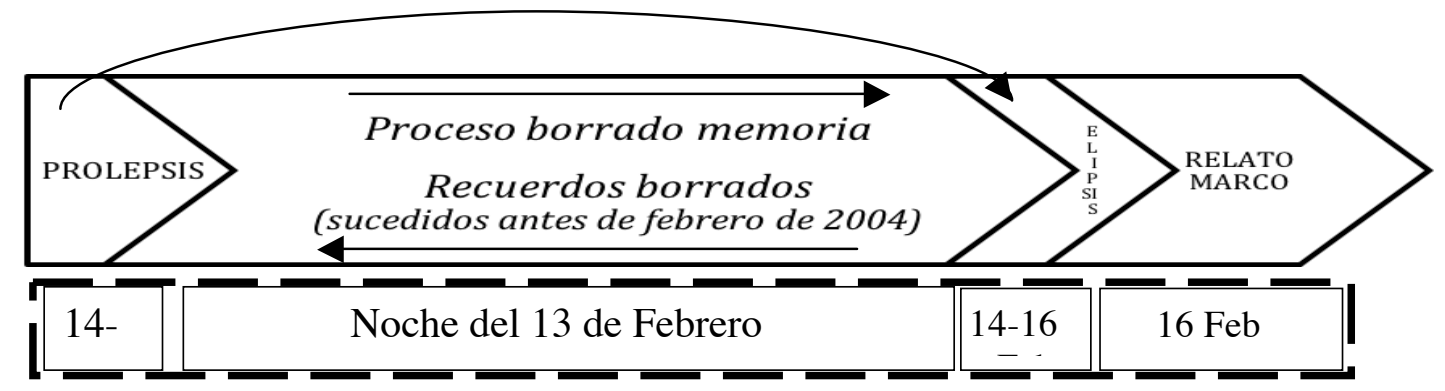

F2. Estructura narrativa de la película. Elaboración propia

Esta estructura no persigue la complejidad en sí misma, sino que, como afirma Piggot, está guiada por el propio orden de la memoria: "Eternal sunshine is structured by memory in two distinct ways, one of which does 
take the form of a progressive revelation yet at the same time refuses to be reduced to a simple flashback or event-shuffling system" (2009, p. 179). Además de estar organizada en un orden cronológicamente inverso, la estructura cuenta con un grado más de dificultad, pues en la parte en la que los recuerdos están siendo borrados las escenas parecen fundirse unas con otras, lo que termina por provocar una indiscernibilidad temporal a la que, por otro lado, contribuyen las imágenes.

Esta forma de estructurar el relato remite también con claridad a los "relatos puzle", tal como propone Buckland. Como este autor señala, este tipo de relatos protagonizados, entre otros, por personajes esquizofrénicos o que han perdido la memoria (2009, p. 6), va más allá de una simple estructura compleja: "A puzzle plot is intricate in the sense that the arrangement of events is not just complex, but complicated and perplexing; the events are not simply interwoven, but entangled" (2009, p. 3). Buckland considera que iOlvídate de mí! plantea una estructura de este tipo en cuanto a la forma que adquiere el relato, pero no tanto en cuanto a la complejidad de la historia narrada. Se trata de un recurso que permite, por una parte, capturar la esencia del objeto representado y, por otra, duplicar la experiencia cognitiva del recuerdo en el espectador. Así, afirma también Miklos Kiss, la esencia de esta complejidad no solo reside en una estructura que puede ser analizada narratológicamente, sino sobre todo en la confusión generada y experimentada por el espectador (2013, p. 237). Por esto, un estudio de carácter estructural resulta insuficiente para comprender el alcance de esta película como representación cinematográfica de la memoria personal.

\subsection{Rasgos característicos de la memoria personal}

Dada la limitación del acercamiento narratológico para una comprensión cabal de la naturaleza de iOlvídate de mí! como película de memoria, resulta necesario ahondar en el modo en que esta película representa la memoria personal. Para ello, pasamos ahora a examinar cómo se despliegan en la cinta los tres rasgos característicos que hemos señalado en este tipo de filmes: subjetividad, indiscernibilidad temporal y performatividad (2017, pp. 182- 
186), lo que nos permitirá captar de modo más acabado la forma en la que Gondry ha expresado la dinámica de la memoria como facultad humana.

Antes de entrar en el análisis propiamente dicho, resulta pertinente una breve presentación de estos tres rasgos, que contextualicen el modo en que articulan la representación fílmica de la memoria personal. En primer lugar, la noción de subjetividad se vincula al carácter personal del acto de rememoración, lo que implica que las películas de memoria están narradas desde un punto de vista esencialmente subjetivo y que sus imágenes no persiguen tanto una representación fidedigna de los hechos pasados tal y como sucedieron, sino más bien la revisión o reactualización visual de tales eventos por parte del personaje que está recordando. En segundo lugar, la indiscernibilidad temporal remite a la articulación de las películas de memoria como relatos que pivotan sobre una apreciación personal del tiempo. Esto es, replican la forma en la que el sujeto percibe la dimensión temporal mientras recuerda. Teniendo en cuenta que la lógica que rige el acto mnemónico escapa a una estructura narrativa clásica (pues el pasado se recupera siempre desde el presente y además es habitual que se den distorsiones, vacilaciones $\mathrm{u}$ olvidos), no parece extraño que estos filmes muestren de modo explícito la conjunción del pasado y del presente que acontece en la memoria. La performatividad, por último, apunta a la necesidad de representar la memoria como un proceso en construcción que nunca se completa del todo. Este enfoque performativo lleva consigo el empleo en las películas de memoria de técnicas autorreflexivas que ponen en cuestión las imágenes que representan los recuerdos y que invitan al espectador a generar un diálogo con la obra fílmica.

\subsubsection{Subjetividad}

Para adquirir un conocimiento más profundo del modo en que la película representa la subjetividad, nos centramos ahora en la parte central del filme, cuando se produce el proceso de borrado. Las dos líneas narrativas de esta parte de la película -el desarrollo del borrado en la habitación de Joel y las escenas que representan los recuerdos que están siendo extraídos- no discurren de forma paralela, sino que se entrelazan influyéndose 
mutuamente. Así, los problemas técnicos que tienen lugar en la habitación se reflejan en la memoria de Joel, mientras que su afán por detener el procedimiento afecta también al plano tecnológico, condicionando la narración de esa otra línea argumental.

Aunque la película representa el contenido de la memoria del protagonista, también enfatiza la postura de éste como sujeto activo en el proceso mnemónico mediante numerosos primeros planos que evidencian su dificultad o desconcierto para comprender y dar sentido a sus evocaciones. $\mathrm{Al}$ comenzar el procedimiento, Joel parece no ser consciente de asistir a sus propios recuerdos. Pero a raíz de un problema técnico que le devuelve al recuerdo ya eliminado de la consulta en Lacuna, Joel experimenta cierta sensación de déjà-vu y descubre que esas imágenes extrañas provienen de su propia memoria. Se produce entonces un momento epifánico en el que Joel cae en la cuenta de que está siendo sometido a una técnica de borrado y de que su mente se encuentra en una zona ucrónica entre la realidad presente y un tiempo pretérito. A partir de aquí, Joel afrontará sus recuerdos desde una postura autoconsciente. Si bien al principio se alegra de la decisión de erradicar sus memorias, termina por arrepentirse a medida que el proceso alcanza los recuerdos más gratos de su relación con Clementine. La trama desarrollada en este fragmento es identificada acertadamente por Day como una trama de "re-casamiento" -variante típica de la comedia clásica, conocida en inglés como remarriage comedy- ya que, a través de su estructura inversa, la historia relatada presenta una ruptura amorosa y su posterior reconciliación y “re-casamiento" (2011, pp. 132-154).

Toda esta línea narrativa presenta la memoria de forma expresiva, sirviéndose de la narración y de la imagen para mostrar los recuerdos del pasado inmediato y lejano del personaje. La primera ocasión en que se reproducen los recuerdos de Joel se localiza justo después de que Stan y Patrick accedan al piso de Joel y lo encuentren desplomado en el suelo debido al efecto del somnífero provisto por Lacuna. Tras esta escena, observamos a Joel con el pijama azul de Lacuna y tumbado sobre la cama con los ojos abiertos. De forma borrosa vemos que alguien se encuentra al fondo 
de la habitación de Joel: gracias a su voz le identificamos como el vecino de la conversación mantenida sobre San Valentín pocos minutos antes. La escena cambia rápidamente a un plano similar al mostrado durante aquella conversación, pero esta vez el plano adquiere un tinte subjetivo al situar la cámara muy cerca del rostro de Joel. Esta escena funciona como una transición que separa las dos líneas narrativas principales, tanto por la temporalidad dominante en la escena como por la focalización, que durante el largo fragmento de rememoraciones será interna, anclada en el personaje de Joel $^{1}$.

Desde la escena del recuerdo de una muñeca, el espectador se hace consciente de la marcada subjetividad de esta secuencia en la que los hechos, lejos de presentarse como una sucesión de eventos objetivos acaecidos en el pasado, lo hacen reconfigurados por la memoria de Joel. El carácter subjetivo de la memoria se pone de manifiesto a través del punto de vista, y mediante otros recursos visuales -como los marcos borrosos, los planos de percepción o la iluminación expresiva- que configuran la imagen según la memoria olvidadiza que se quiere representar. La focalización interna -tanto de carácter cognitivo como perceptivo (Jost, 1989, pp. 119-150)- enfatiza el carácter personal de la memoria. A pesar de que el equipo de Lacuna entra en cierta forma a los recuerdos del protagonista, tan solo él puede evocarlos y reactualizarlos de modo personal. Mientras que Stan, Patrick y Howard acceden a esas memorias a través de una tecnología que las ubica espacialmente en la mente, el proceso de borrado reactualiza los recuerdos haciendo que Joel vuelva a re-vivirlos en su cabeza siempre desde su punto de vista. Debido al proceso de borrado, con frecuencia encontramos partes del plano más iluminadas que otras, dejando en la oscuridad aquello que parece estar siendo anulado de la mente del protagonista. Así ocurre cuando Joel y Clementine tratan de huir del borrado mientras una especie de foco luminoso les enmarca y persigue. El deseo de Joel de frenar el procedimiento se plasma también en otro recurso visual que enfatiza la subjetividad del acto

1 Campora afirma que estas dos líneas narrativas, que él denomina walking strand e internal-subjective strand, se distinguen, además de por la focalización, por su naturaleza ontológica, por sus diferencias epistemológicas y por una estética radicalmente opuesta (2009, p. 123). 
rememorativo, al mostrar al sujeto que recuerda -y que va olvidandorealizando una especie de viaje a través del paisaje mental de sus evocaciones. Así, afirma Kilbourn, la película rejuvenece el género del psicokatabasis, configurándose como un viaje a través de la memoria (2012, p. 128). Joel adopta un papel activo en la configuración de la memoria e inicia un viaje que, en vez de orientarse a buscar sus recuerdos, se centra en escapar de la tecnología que pretende eliminarlos.

De forma muy expresiva, la cámara también presenta imágenes derivadas del olvido que adquieren un tono surrealista de gran interés, debido a la focalización interna y a la subjetivización. Así se observa en los rostros desfigurados o borrados que, a través de técnicas digitales, muestran a las personas desde una mente dañada por el olvido. Asimismo, pequeños detalles se ven afectados por esta memoria confusa, generando cambios visuales. Esto le pasa al regalo que Joel pretendía regalar a Clementine, que cambia de tamaño en las dos escenas en que es recordado. Además, varias escenas parecen entremezclar los decorados y los personajes de los momentos rememorados, produciendo situaciones extrañas donde los eventos son claramente focalizados desde la mente confusa de Joel. Podemos encontrar estas fusiones de escenas especialmente al final de la secuencia de los recuerdos, cuando la memoria de Joel se encuentra ya casi desintegrada, como ocurre con la casa vacía de la playa, que es invadida por el agua, o con el coche que aparece lleno de arena y objetos de la playa.

Además de esa subjetivización, la película representa la memoria olvidadiza mediante el recurso a lo que MacDougall denomina signos de ausencia ${ }^{2}$. A lo largo de la película ciertas imágenes evidencian la pérdida y el vacío que deja el olvido mediante planos modificadas digitalmente o mediante espacios vacíos. Así, el proceso de borrado se llena de ausencias que van cobrando peso en el filme, como la librería en la que los libros se desvanecen hasta desaparecer, las escenas en las que Clementine es arrebatada del lado del

\footnotetext{
2 MacDougall identifica tres tipos de signos externos a través de los cuales las películas suelen representar la memoria -signos de supervivencia, signos de semejanza y signos de sustitución-, que complementa con un cuarto tipo: los signos de ausencia, cuyo empleo considera menos generalizado (1999, pp. 29-37).
} 
protagonista o los momentos en que su ausencia sorprende a Joel, como cuando juega con ella en su infancia. Una de las escenas más significativas que muestran la desaparición súbita de Clementine recurriendo a los signos de ausencia es aquella en la que, mientras Mary recita el poema de Alexander Pope que da el título original a la película, vemos a Joel y Clementine disfrutando juntos en una celebración con elefantes por las calles de la ciudad. Las imágenes de ese momento de diversión de la pareja terminan con un plano de Joel inquieto buscando a Clementine entre la multitud, lo que produce cierta reverberación con el poema de Alexander Pope ("Eternal sunshine of the spotless mind! / Each pray'r accepted, and each wish resign'd”). La película recurre también con insistencia a imágenes marcadas por la decadencia y la ruina que evidencian la desaparición de los recuerdos. Por ejemplo, al terminar la secuencia situada en la infancia del protagonista, su casa se transforma en una estancia vieja y abandonada, igual que la casa de la playa donde estuvo con Clementine el día en que se conocieron, que se derrumba poco a poco hasta venirse abajo al completar el borrado de los recuerdos de Joel.

\subsubsection{Indiscernibilidad temporal}

El relato focalizado de estas memorias no solo evidencia el carácter subjetivo del acto mnemónico, sino también la cualidad temporal de la memoria, que se deriva de la experiencia a la que se enfrenta el protagonista al recordar, un proceso que se entiende como actualización de eventos pasados. Este entrelazamiento de las dimensiones temporales remite a las imágenes-cristal de Deleuze, como bien apunta Rawle, quien afirma que el filme se estructura narrativamente según dichas imágenes-cristal, puesto que contrapone las acciones del personaje desde su experiencia y percepción actual a los momentos virtuales del pasado recordado, vinculándolos de tal modo que lo actual y lo virtual resultan indiscernibles (2012, p. 39). Con un planteamiento cercano, Pigott afirma que los recuerdos de Joel se sustentan en la simultaneidad entre el presente y el pasado de las escenas, lo que rompe con la consideración clásica de los flashbacks (2009, p. 178). No obstante, a pesar de la mezcla de capas temporales, estas escenas se presentan como vueltas al 
pasado (o analepsis) externas y completivas, pues en su mayoría presentan eventos no narrados en el relato marco. Así, a través de estas imágenes se hace posible completar el puzle de la relación de Joel y Clementine, desde el día en que se conocen hasta la decisión del protagonista de someterse al borrado. Algunas de las escenas presentadas como sucesos pasados se repiten, configurándose como una analepsis repetitiva. Esas escenas, sin embargo, así como las de los recuerdos de la consulta en Lacuna, no son repetidas de forma exacta, sino con ligeras modificaciones, puesto que, siguiendo la lógica interna de la película, se trata de un regreso a una memoria ya borrada con anterioridad.

La naturaleza de estas analepsis rehúye un análisis narratológico tradicional. Ya al comenzar la secuencia del borrado, las primeras imágenes de los recuerdos indican que las escenas mostradas, aunque pueda parecerlo, no se configuran como un flashback canónico. La indiscernibilidad temporal entre el presente y los eventos rememorados se hace todavía más evidente desde el momento en que Joel empieza a ser consciente de que se encuentra dentro de su mente y de que los hechos que observa son sus propias memorias siendo borradas. Aunque la secuencia temporal resulta en principio comprensible porque mantiene cierta estructura cronológica inversa, poco a poco se va planteando desde una percepción psicológica personal que se construye mediante un montaje fragmentario y unos planos imposibles. Las imágenes que conforman esta narración visual atípica se constituyen, empleando la terminología de MacDougall (1992, p. 31), como signos de semejanza que ofrecen imágenes similares a los eventos rememorados, pero poniendo de relieve el carácter falible de la memoria y las confluencias entre lo real y lo virtual. Esta confluencia se da especialmente en aquellas escenas que muestran un suceso pretérito a la vez que Joel lo vive conscientemente desde el presente, como, por ejemplo, cuando Joel persigue a Clementine por la calle tras haber discutido. Ahí el protagonista, situado en el papel que tuvo en el pasado, pero consciente de que lo observa desde otra época, le confiesa a Clementine que está borrándola de su memoria. Este recuerdo, así como otros de marcado carácter surrealista -como cuando se ven rostros difuminados o personas que cambian de apariencia-, se construyen como 
signos de semejanza gracias a los efectos visuales que contribuyen a producir ese desdoblamiento temporal.

Esta temporalidad doble puede producirse, como en la escena recién mencionada, a través de las acciones y los diálogos de los personajes, o también mediante imágenes que crean una continuidad entre presente y pasado. Hay dos escenas situadas en la infancia de Joel que proponen una aproximación visual a esta temporalidad personal. Una de ellas es la que se desarrolla en la cocina de su casa. Mediante distintos efectos visuales, Joel es mostrado en su madurez, pero con el tamaño y el comportamiento de un niño, mientras que Clementine pasa a representar a una amiga de la madre de Joel, siendo plenamente autoconsciente. La otra escena transcurre en el jardín de la casa y plantea una postura aún más expresiva, intercalando, tanto en el plano visual como en el sonoro, a los protagonistas como adultos y como niños. Los adultos y los niños visten la misma ropa y actúan de forma parecida, dando a entender que esa memoria ha conseguido incluir la presencia actual de los sujetos en el momento y experiencia del pasado, así como elementos recordados de otros imaginarios, puesto que Clementine no podría encontrarse como niña en aquellos recuerdos.

Decíamos antes que la indiscernibilidad temporal propia de la imagen-cristal deleuziana activa también la memoria del espectador. Los continuos trasvases entre la narración de los recuerdos y la narración del proceso de borrado exigen del público una revisión constante de su propia memoria del visionado de la película, en la línea de lo que Dzialo ha denominado como "frustrated time narration" (109-110). Afirma Rawle que la cinta genera, asimismo, un efecto de déjà-vu en la audiencia, conseguido a través de las repeticiones y la estructura circular que produce la prolepsis con la que arranca el filme (2012, p. 40). El espectador se enfrenta en numerosas ocasiones a escenas que dan cuenta de esa indiscernibilidad temporal, como la de la consulta en Lacuna o las noches en el río Charles completamente congelado, pues son reconocidas como imágenes ya vistas. La estructura cronológica inversa mantiene al público en un continuo interrogante, en busca de una resolución correcta de la narración y de un orden adecuado de 
los diferentes eventos. De todo esto se deduce que el diseño visual y la configuración narrativa consiguen producir en el espectador un efecto cercano al experimentado por Joel al enfrentarse al proceso de borrado, como si estuviera involucrado en la experiencia del acto de memoria.

\subsubsection{Performatividad}

Esta manera de involucrar al espectador nos remite al estudio del tercer rasgo que hemos señalado para las películas de memoria, la performatividad (2017, pp. 185-186), para indagar en el modo en que iOlvídate de mí! representa el hecho de recordar como un proceso en construcción. Resulta claro, por lo visto hasta ahora, que el filme se sustenta sobre la idea de que los recuerdos no son contenidos fijados y almacenables, sino que requieren de una actualización de los eventos pasados. De aquí que los sucesos rememorados no sean mostrados como algo inmutable, ni las escenas que representan esos recuerdos como simples flashbacks, sino que exhiben acciones en construcción, enfatizando su carácter performativo. Las escenas rememoradas por Joel no son consideradas como una ventana al pasado, ni tampoco como una escena de otro tiempo en la que encontramos al sujeto interactuando desde su presente, como puede suceder en algunos flashbacks de memoria. 3 Más bien los recuerdos de Joel van construyéndose, o mejor, actualizándose, a medida que los técnicos van eliminándolos, y en función del arrepentimiento del protagonista, que intenta por todos los medios detener el borrado, modificando sus memorias de forma autoconsciente.

De ahí que la representación de los recuerdos de Joel no acaba de ajustarse a la categoría de vuelta al pasado convencional, pues el personaje no se sitúa propiamente en un presente desde el que recuerda el pasado. Por eso, resulta pertinente analizar estas escenas no solo como analepsis -en función de su relación temporal con el relato marco-, sino también como metalepsis, en cuanto que plantean un cambio de nivel narrativo. Podemos entender que Joel no es testigo de unos eventos del pasado, sino que, más bien, es quien

\footnotetext{
3 El término "flashback de memoria" como tal lo propone Michael Pigott, quien considera que existen dos formas distintas de flashback que se distinguen por la forma en que la subjetividad de la memoria influye en la analepsis: los convencionales (independientes, en su terminología); y los que vinculan el presente del sujeto con su experiencia y recuerdo del pasado, que él denomina memory-flashback (Pigott, 2009, p.179).
} 
rompe la barrera que separa el mundo real, en el que están borrando su memoria, del mundo interior y subjetivo de su mente. En este sentido, cabe afirmar que la presencia autoconsciente de Joel en las escenas reactualizadas por su memoria se asemeja más a las incursiones de personajes como el protagonista de Medianoche en París (Midnight in Paris, Woody Allen, 2011) en los años veinte, o a la relación entre los personajes de Más extraño que la ficción (Stranger than fiction, Marc Forster, 2006). Joel aparece, en primer lugar, en los espacios de su mente, emplazado ahí por las epifanías de la memoria involuntaria, para después decidir, mediante la memoria voluntaria, los lugares y tiempos que quiere visitar. En esta misma línea se sitúa el análisis de Campora, quien recupera el término "narración multiforme” de Murray (1997) para explicar cómo la película presenta varios planos narrativos sobre realidades ontológicas distintas para representar la perspectiva subjetiva interna del personaje (2009, p. 122). En la cinta de Gondry distinguiremos, por tanto, dos niveles ontológicos entre los que Joel se desplaza de forma descendente, puesto que los recuerdos representados no se encuentran en el mismo nivel de realidad que la historia del borrado, sino en un nivel metadiegético, según términos genettianos (2004, pp. 2931).

La película propone distintos tipos de metalepsis que enfatizan el carácter performativo de la memoria. La línea narrativa que presenta los recuerdos de Joel no nos muestra los eventos pasados vividos por él, sino su propia reconstrucción mental de dichos eventos. Resulta interesante comprobar cómo en iOlvídate de mí! las primeras escenas de los recuerdos de Joel parecen no evidenciar que lo que observamos son interpretaciones, o más bien construcciones, del protagonista, sino que se presentan como meros relatos de los sucesos pasados. Estas primeras escenas sí marcan, sin embargo, cierta separación de niveles diegéticos, siempre de forma muy sutil, y mediante el recurso al sonido. Si las analizamos con detenimiento, comprobamos cómo tras finalizar la representación de un recuerdo se escucha el sonido del ordenador de Stan, que indica que una memoria ha sido borrada, configurando estos nexos sonoros que enlazan los distintos niveles de la película como metalepsis retóricas. Afirma también Campora 
que este tipo de metalepsis son las que encontramos en las primeras escenas en las que Joel persigue a Clementine en la calle que se desdibuja, puesto que escuchamos la voz de Stan y Patrick en lo que queda como un puente entre las dos líneas argumentales (2009, p. 126). Estas escenas, sin embargo, cobran un nuevo significado cuando Joel comienza a oír las voces de los técnicos y estos advierten en el ordenador una especie de eco de sus propias palabras en la mente de Joel. En este momento comprendemos, y Joel también lo hace, que no estamos siendo testigos de unos eventos pasados presentados mediante analepsis, sino que estamos percibiendo dos órdenes ontológicos distintos e interrelacionados. Los recuerdos de Joel se generan debido a la acción sucedida en el nivel intradiegético, que a su vez es influido por las acciones desempeñadas por Joel en su mente al huir del borrado modificando sus memorias o resituándolas en otros paisajes mentales. Las metalepsis que encontramos en el filme vienen motivadas, por tanto, por los distintos planos de realidad que encontramos en el relato, que no solo evidencian la cualidad performativa del recuerdo, sino también su duplicidad temporal o indiscernibilidad.

\section{Conclusiones}

Lo expuesto hasta aquí nos lleva a afirmar que iOlvídate de mí! es un filme que plasma con acierto y de forma creativa las cualidades fundamentales de la memoria personal. A través del tema desarrollado y de las decisiones formales empleadas, la cinta logra expresar la complejidad de la representación fílmica de la memoria personal, pues pone de relieve la subjetividad del acto de recordar, la indiscernibilidad temporal que provoca, y su carácter performativo, lo que nos lleva a entender esta obra como un caso paradigmático de las películas de memoria.

La subjetividad inherente al acto de recordar sobre todo se hace presente en la parte central del filme y se asocia a la postura autoconsciente que los personajes adoptan ante sus propios recuerdos. El recurso a la focalización interna, el diseño de planos con tintes subjetivos y surrealistas, las imágenes del protagonista viajando a través del paisaje mental de sus evocaciones o los 
signos de ausencia que dan cuenta de la dimensión olvidadiza de la memoria evidencian el carácter personal de la rememoración. La indiscernibilidad temporal se refleja, por su parte, en la actualización de los eventos pasados desde el tiempo presente, razón por la que lo virtual y lo actual aparecen fusionados a lo largo del metraje. Este entrecruzamiento temporal se consigue gracias a la ausencia de una secuenciación lógica de los hechos. A ello contribuyen el montaje fragmentario, la estructura circular y el uso de analepsis repetitivas que insisten en escenas que, si bien a primera vista resultan prácticamente idénticas, presentan no obstante pequeñas modificaciones que terminan por poner a prueba la propia experiencia mnemónica del espectador. Por último, la performatividad remite a la comprensión de la memoria como un proceso en construcción. En la película se advierte que los recuerdos no son contenidos fijos e inmutables, sino que se actualizan cada vez que la mente pone en marcha un proceso de rememoración. Por esta razón el personaje principal no es mostrado como un mero testigo de su propio pasado, sino más bien como quien consigue romper la barrera entre el mundo real y el mundo interior de su mente. Todo esto abre el relato a multitud de cambios de nivel narrativo y a distintos tipos de metalepsis que destacan la presencia autoconsciente del protagonista en las escenas reactualizadas por su memoria.

\section{Referencias bibliográficas}

Bergson, H. (1946), The Creative Mind: An Introduction to Metaphysics. New York: Citadel Press.

Buckland, W. (2009). Puzzle Films: Complex Storytelling in Contemporary Cinema. Chichester: Wiley-Blackwell.

Campora, M. (2009). Art cinema and New Hollywood: Multiform narrative and sonic metalepsis in Eternal Sunshine of the Spotless Mind. New Review of Film and Television Studies, 7 (2), 119-131.

Ciancio, M. B. (2013). Labyrinths and Lines of Memory in Documentary Film. Memoria del saqueo and Los rubios from a Philosophical Perspective. Latin American Perspectives, 40 (1), 101-113.

Cuevas, E. (2001). Focalización de los relatos audiovisuales. Trípodos, 11, $123-136$. 
Cuevas, E. (2009). La narratología audiovisual como método de análisis. Portal de la Comunicación, 1-12. http://www.portalcomunicacion.com/uploads/pdf/53_esp.pdf

Day, W. (2011). I Don't Know, Just Wait: Remembering Remarriage in Eternal Sunshine of the Spotless Mind. En D. Larocca (ed.), The Philosophy of Charlie Kaufman (pp. 132-154). Lexington: University Press of Kentucky.

Deleuze, G. (1987). La imagen-tiempo: Estudios sobre cine II. Barcelona: Paidós.

Deleuze, G. (1991). La imagen-tiempo: Estudios sobre cine I. Barcelona: Paidós.

Del Rincón, M., Torregrosa, M., Cuevas, E. (2017). La representación fílmica de la memoria personal: las películas de memoria. $Z E R, 22$ (42), 175188. DOI: $10.1387 /$ zer. 17842

Dzialo, C. (2009). Frustrated Time Narration: the Screenplays of Charlie Kaufman. En W. Buckland (ed.), Puzzle Films: Complex Storytelling in Contemporary Cinema (pp. 107-128). Chichester: Wiley-Blackwell.

Erll, A. (2011). Memory in Culture. Chippenham and Eastbound: Palgrave Macmillan.

García-Sahagún, M (2016). La crisis de la identidad personal en el protagonista del cine contemporáneo (Tesis doctoral). Universidad Complutense de Madrid https://eprints.ucm.es/44286/1/T39119.pdf

Gaudreault, A., Jost, F. (1995). El relato cinematográfico. Cine y narratología. Barcelona: Paidós.

Genette, G. (1989). Figuras III. Barcelona: Lumen.

Genette, G. (2004). Metalepsis. De la figura a la ficción. Buenos Aires: Fondo de Cultura Económica.

Grass, M. (2009). Imagen latente y Los rubios: Performatividad cinematográfica y estética de la memoria en el cine latinoamericano (Tesis Doctoral, Universidad de Chile), Recuperado de http://repositorio.uchile.cl/tesis/uchile/2009/grass_m/html/indexframes.html

Jost, F. (1989). L'Oeil-caméra. Entre film et roman. $2^{\text {a }}$ ed. revisada y aumentada. Lyon: Presses Universitarires de Lyon.

Kilbourn, R. J. A. (2012). Cinema, Memory, Modernity: The representation of Memory from the Art Film to Transnational Cinema. Nueva York: Routledge.

Kiss, M. (2012). Navigation in Complex Films: Real-life Embodied Experiences Underlying Narrative Categorisation. En J. Eckel, B. Leiendecker, D. Olek (eds.), (Dis)Orienting Media and Narrative Mazes (pp. 237-251). Bielefeld: Transcript.

MacDougall, D. (1992). Films of Memory. Visual Anthropology Review, 8 (1), 29-37. 
MacDougall, D. (1998). Films of Memory. En D. MacDougall (ed.), Transcultural Cinema (pp. 231-244). Princeton: Princeton University Press.

Murray, J. H. (1997). Hamlet on the Holodeck: The Future of Narrative in Cyberspace. Nueva York: Free Press.

Piggot, M. (2009). Manifesting a Mutant Past in Eternal Sunshine of the Spotless Mind. En C. Lee (ed.), Violating time: History, Memory and Nostalgia y Cinema (pp. 170-190). Nueva York: Continuum.

Rawle, S. (2012). Reconstructing the Past: Visual Virtuality in Eternal Sunshine of the Spotless Mind. En A. Shinha, T. McSweeney (eds.), Millennial Cinema: Memory in Global Film (pp. 37-54). Londres y Nueva York: Wallflower Press.

Sperb, J. (2005). Internal Sunshine: Illuminating Being-Memory in Eternal Sunshine of the Spotless Mind. Kritikos, 2. https://intertheory.org/sunshine.htm

Vidal, F. (2007). Eternal Sunshine of the Spotless Mind and the cultural history of the self. WerkstattGeschichte, 16 (45), 96-109. 